\title{
Features of the Pulsed Treatment of Silicon Layers Implanted with Erbium Ions
}

\author{
R. I. Batalov ${ }^{a, *}$, R. M. Bayazitov ${ }^{a}$, R. M. Nurutdinov ${ }^{a}$, D. I. Kryzhkov ${ }^{b}$, P. I. Gaiduk ${ }^{c}$, \\ C. P. Marques ${ }^{d}$, and E. Alves ${ }^{d}$ \\ ${ }^{a}$ Kazan Physical-Technical Institute, Russian Academy of Sciences, Sibirskii trakt 107, Kazan, 420029 Russia \\ *e-mail: batalov@kfti.knc.ru \\ ${ }^{b}$ Institute for Physics of Microstructures, Russian Academy of Sciences, ul. Ul'yanova 46, Nizhni Novgorod, 603950 Russia \\ ${ }^{c}$ Belarusian State University, pr. Nezavisimosti 4, Minsk, 220030 Belarus \\ ${ }^{d}$ Nuclear and Technological Institute, Estrada Nacional 10, Sacavem PT-2686-953, Portugal
}

Received August 14, 2008

\begin{abstract}
The formation of thin-film solid solutions of erbium in silicon and synthesis of erbium silicides were performed using continuous implantation of silicon with erbium ions followed by pulsed ion-beam treatment. Structural and optical properties of formed $\mathrm{Si}$ :Er layers were studied by Rutherford backscattering, transmission electron microscopy, and low-temperature photoluminescence. The dependences of erbium redistribution, the microstructure of Si:Er layers, and their photoluminescence in the near-IR region on the erbium concentration and pulsed treatment conditions were determined.
\end{abstract}

DOI: $10.1134 / \mathrm{S} 102745100904020 \mathrm{X}$

\section{INTRODUCTION}

One of the promising directions in the development of silicon structures emitting in the range of $1.5-1.6 \mu \mathrm{m}$ is Si doping with rare-earth Er atoms. Due to intracenter optical transitions between ${ }^{4} I_{13 / 2} \longrightarrow{ }^{4} I_{15 / 2}$ levels in the $\mathrm{Er}^{3+}$ ion, luminescence at the wavelength $\lambda=1.54 \mu \mathrm{m}$ is characterized by a narrow line and is almost independent of the temperature and matrix with introduced $\mathrm{Er}$ atom [1]. The method of ion implantation is widely employed to form light-emitting Si:Er solid solutions [2] and erbium silicide films on silicon promising for use as Schottky barriers in microelectronics [3]. A significant disadvantage of the method of ion implantation is considerable damage of the Si lattice during introduction of heavy $\mathrm{Er}^{+}$ions. To eliminate radiation damage and to optically and electrically activate an impurity, high-temperature annealing $\left(T>900^{\circ} \mathrm{C}\right)$ is usually performed. However, along with elimination of simple defects, such heat treatment can result in the formation of more complex defects (dislocations, dislocation loops) [4] and erbium silicide precipitates which decrease the efficiency of Er luminescence. Moreover, high-temperature annealing causes rapid diffusion of Er atoms to the $\mathrm{Si}$ crystal depth, which creates difficulties in the fabrication of light-emitting diodes due to strongly spread profiles of introduced atoms.

Pulsed treatment of implanted Si layers by nanosecond laser, ion, or electron beams can be an alternative to thermal annealing. Pulsed treatment allows localization of annealing of an amorphous material over its depth (smaller than $1 \mu \mathrm{m}$ ) and area. Moreover, due to high melting and crystallization rates, pulsed exposures result in the formation of epitaxial layers with a lowered defect level [5]. It should be noted that the use of pulsed treatment of Si:Er layers is rarely reflected in the literature [6], which stimulates studies in this direction. In this work, we studied the features of pulsed ionbeam treatment (PIBT) of Si layers implanted with $\mathrm{Er}^{+}$ ions.

\section{EXPERIMENTAL}

With the purpose of forming thin-film Si:Er solid solutions and erbium silicides, $n$-Si(100) wafers grown by the Czochralski method were implanted with $100-\mathrm{keV}$ $\mathrm{Er}^{+}$ions to doses $\Phi=10^{16}$ and $10^{17} \mathrm{~cm}^{-2}$ at room temperature. To eliminate radiation defects, $\mathrm{Si}$ samples were subjected to PIBT. A pulsed accelerator generated nanosecond ( $\tau=50 \mathrm{~ns}$ ) ion beams with energy $E=300 \mathrm{keV}$, consisting of carbon $(\sim 80 \%)$ and hydrogen $(\sim 20 \%)$. The total ion dose per pulse did not exceed $10^{13} \mathrm{~cm}^{-2}$. The energy density $\left(W=1-2 \mathrm{~J} / \mathrm{cm}^{2}\right)$ and the number of pulses $(N=1-10)$ were varied during PIBT. In addition to PIBT, Si samples were subjected to 20-min thermal annealing (TA) at $T=800^{\circ} \mathrm{C}$.

The depth distribution of implanted Er atoms after ion implantation and PIBT was studied by Rutherford backscattering (RBS), including ion channeling, using a $2-\mathrm{MeV}$ helium beam. The microstructure and phase composition of Si:Er layers was studied by transmis- 
sion electron microscopy (TEM). Photoluminescence (PL) of Si:Er layers was studied in the near-IR range $(1-1.7 \mu \mathrm{m})$ at $T=77 \mathrm{~K}$. The PL signal was excited by continuous radiation of an argon laser $(\lambda=514.5 \mathrm{~nm})$ with power $P=200 \mathrm{~mW}$. PL was recorded using a BOMEM Fourier spectrometer with a cooled germanium detector.

\section{RESULTS AND DISCUSSION}

Figure 1 shows unoriented and oriented $(\mathrm{Si}\langle 100\rangle)$ RBS spectra of Si samples after ion implantation with various doses and PIBT. We can see that, due to the low implantation energy, Er atoms are concentrated in a narrow range corresponding to the Gaussian peak near the surface. Spectrum processing shows that the Er peak halfwidth and amorphous $\mathrm{Si}$ layer thickness increase with the dose from 55 and $110 \mathrm{~nm}$ for $\Phi=$ $10^{16} \mathrm{~cm}^{-2}$ to 80 and $130 \mathrm{~nm}$ for $\Phi=10^{17} \mathrm{~cm}^{-2}$, respectively. We can see from Fig. 1a that PIBT results in epitaxial recrystallization of the amorphous $\mathrm{Si}$ layer (helium ion beam channeling in the range of channels 450-500) and in displacement of an Er atom fraction to the surface (the narrow peak $\sim 30 \mathrm{~nm}$ thick (segregation)) and to the Si crystal depth (diffusion). The segregation effect is caused by low Er solubility in $\mathrm{Si}$ $\left(\sim 10^{16} \mathrm{~cm}^{-3}\right)$; the small width of the Er peak is caused by the high velocity $(\sim 1 \mathrm{~m} / \mathrm{s})$ of the crystallization front during hardening of the silicon melt. This effect is more pronounced at lower implantation doses $\left(\Phi<10^{16} \mathrm{~cm}^{-2}\right)$, where almost all impurity atoms are displaced into a thin surface peak to $30 \mathrm{~nm}$ thick. In contrast to $\mathrm{Si}$, channeling in the Er peak (channels 750-800) is absent after PIBT, which indicates interstitial Er atom positions in the Si lattice.

In the case of high-dose implantation (Fig. 1b), PIBT results in significant suppression of Er segregation to the surface, since the Er concentration in the implanted layer reaches the eutectic point $\left(\sim 10^{22} \mathrm{~cm}^{-3}\right)$, and the coefficient of the impurity distribution approaches unity. In this case, Er atoms mostly diffuse to the Si crystal depth, and the diffusion tail becomes wider as the number of pulses increases. Rapid diffusion of Er atoms in the $\mathrm{Si}$ melt with diffusivity $D \sim 10^{-4} \mathrm{~cm}^{2} / \mathrm{s}$ results in an almost twofold increase in the initial Er peak width; its initial height approximately corresponding to 40 at \% Er also decreases almost twice. At such a high impurity concentration, erbium silicides are formed, which is seen by an RBS signal drop near the Si surface (channels 460-500). We note that channeling in the Si region after PIBT is less pronounced in this case; this indicates a certain disorder in the implanted layer, which can be associated with the polycrystalline structure of $\mathrm{Si}$ and erbium silicides. The prevalence of diffusion processes over segregation ones and silicide formation at high concentrations of a poorly soluble impurity was also observed in the $\mathrm{Si}-\mathrm{Fe}$ system during pulsed treatments [7].

The microstructure and phase composition of Si layers implanted withEr ${ }^{+}$ions and subjected to PIBT were
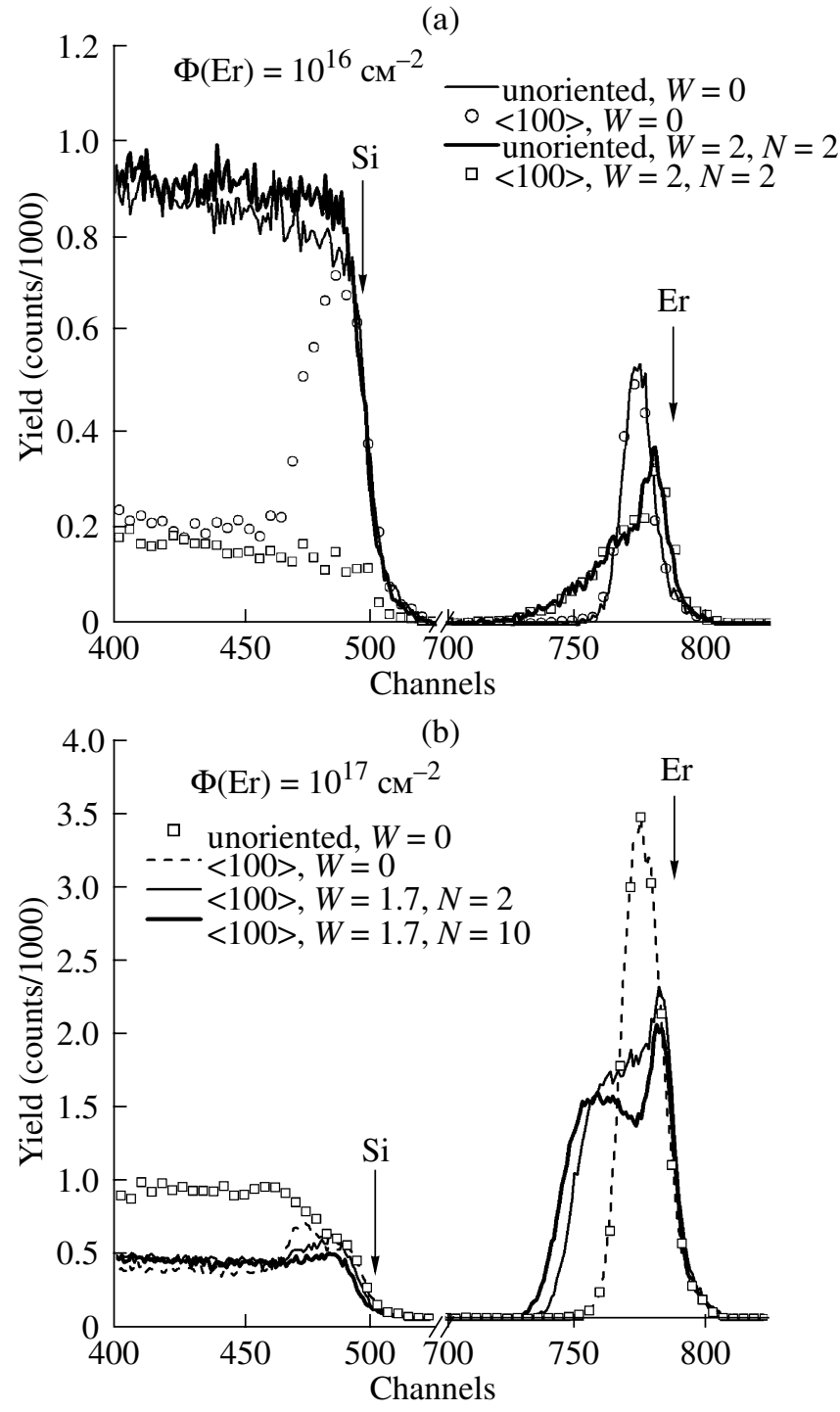

Fig. 1. RBS and channeled ion spectra of $\mathrm{Si}(100)$ samples after ion implantation and PIBT $\left(W=1.7-2 \mathrm{~J} / \mathrm{cm}^{2}, N=2\right.$ 10). Implantation doses are $\Phi=$ (a) $10^{16}$ and (b) $10^{17} \mathrm{~cm}^{-2}$ Vertical arrows indicate the surface position for Si and Er.

studied by TEM and microdiffraction methods. Figure 2 shows the bright-field TEM images of implanted Si layers after PIBT. We can see that PIBT results in the formation of a cellular structure of the implanted layer in the case of low-dose implantation $\left(\Phi=10^{16} \mathrm{~cm}^{-2}\right)$ (Fig. 2a). This structure represents large (to $0.2 \mu \mathrm{m}$ in size) Si cells (columns) threading to the surface. Erbium (dark areas) is concentrated in walls of these columns in the form of erbium silicide precipitates up to $20 \mathrm{~nm}$ in size. Microdiffraction measurements of the cellular structure show the presence of point reflexes associated with silicon and erbium monosilicide (Si:Er), which indicates epitaxial recrystallization of the implanted layer due to PIBT. This result is in agreement with the RBS data (Fig. 1a) where channeling is observed in the implanted layer region after PIBT. The study of the microstructure of implanted 



Fig. 2. Bright-field TEM images of the implanted Si layer after PIBT $\left(W=2 \mathrm{~J} / \mathrm{cm}^{2}, N=2\right)$. Implantation doses are $\Phi=$ (a) $10^{16}$ and (b) $10^{17} \mathrm{~cm}^{-2}$.

Si layers after PIBT and additional TA at temperatures below $900^{\circ} \mathrm{C}$ showed that the cellular structure is highly thermally stable and does not endure significant changes.

In the case of high-dose implantation of $\mathrm{Er}^{+}$ions $\left(\Phi=10^{17} \mathrm{~cm}^{-2}\right)$, the formation of fine grains of silicon and erbium silicides to $40 \mathrm{~nm}$ in size is observed (Fig. 2b). The microdiffraction pattern shows the presence of a large number of rings (up to 20) caused by the formation of polycrystalline $\mathrm{Si}$ and erbium disilicide $\mathrm{ErSi}_{2}$ in the implanted layer. The formation of polycrystalline $\mathrm{ErSi}_{2}$ is in agreement with the data of [3], where (a)

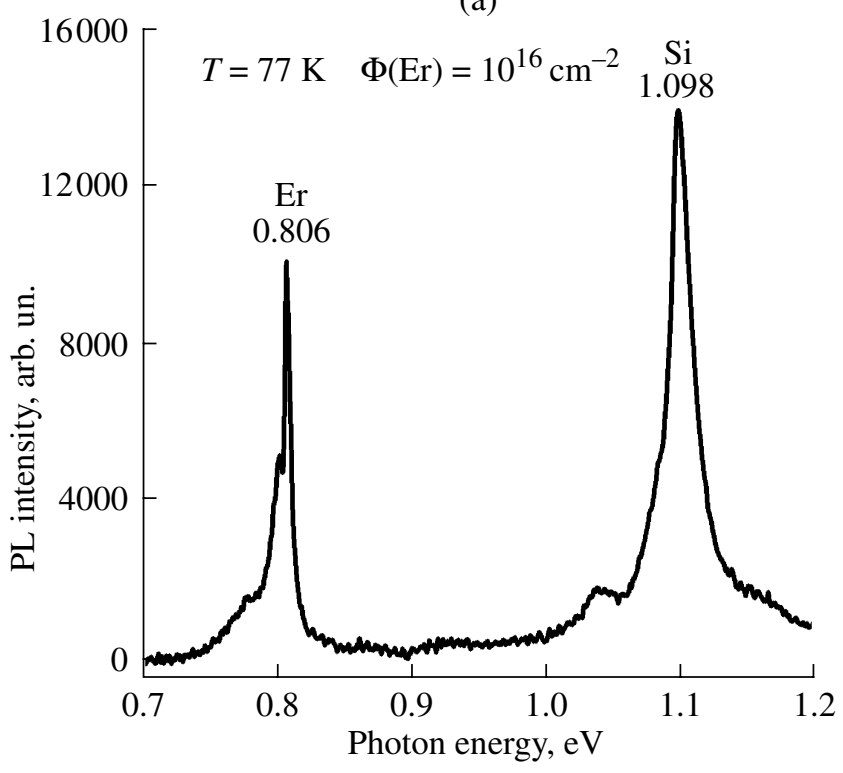

(b)

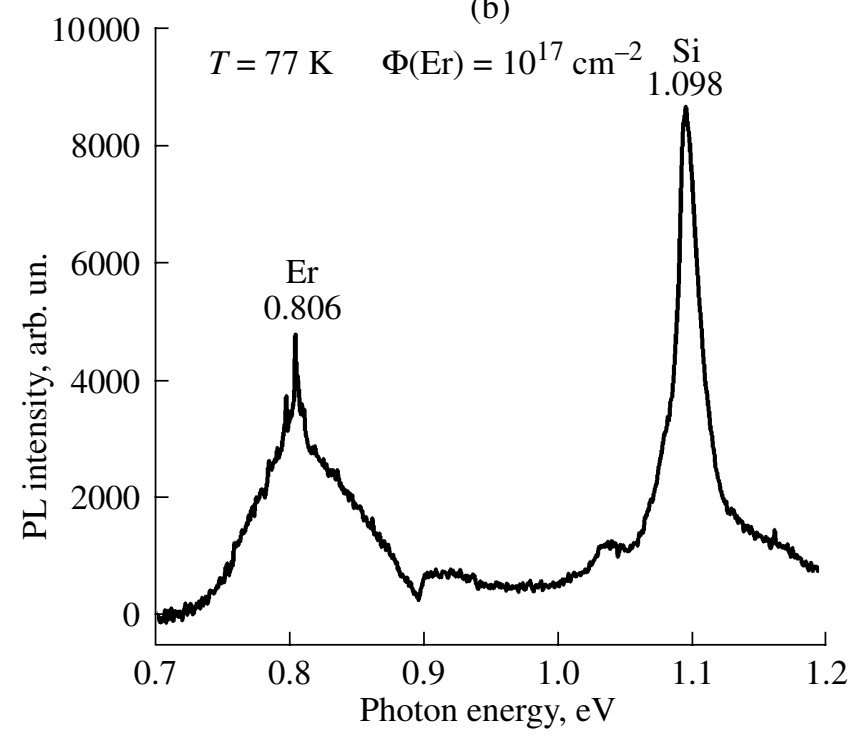

Fig. 3. PL spectra of the implanted Si layer after PIBT ( $W=$ $\left.1.4 \mathrm{~J} / \mathrm{cm}^{2}, N=2\right)$ and additional TA $\left(800^{\circ} \mathrm{C}, 20 \mathrm{~min}\right)$, measured at $T=77 \mathrm{~K}$. Implantation doses are $\Phi=$ (a) $10^{16}$ and (b) $10^{17} \mathrm{~cm}^{-2}$.

high-dose and high-current-density implantation also resulted in the formation of the polycrystalline $\mathrm{ErSi}_{2}$ phase. This is also confirmed by the RBS data (Fig. 1b), according to which, the maximum concentration of the Er atoms decreased from $\sim 40$ to $\sim 20$ at $\%$ due to PIBT.

To study the PL properties in a near-IR region, the Si:Er layers obtained by ion implantation and PIBT were additionally annealed in a furnace at $T=800^{\circ} \mathrm{C}$ for 20 min to eliminate point defects which are nonradiative recombination centers. Figure 3 shows the PL spectra $(T=77 \mathrm{~K})$ of $\mathrm{Si}$ samples in which concentrations of 
Er atoms $\left(\sim 10^{21}\right.$ and $\left.\sim 10^{22} \mathrm{~cm}^{-3}\right)$ significantly exceed their precipitation threshold $\left(\sim 10^{19} \mathrm{~cm}^{-3}\right)$. Both spectra contain two strong peaks at 0.806 and $\sim 1.1 \mathrm{eV}$, and the intensity of the latter peak is about one and a half times higher. This peak is caused by Si band-edge luminescence emitted from a depth of $\sim 1 \mu \mathrm{m}$, i.e., the penetration depth of radiation of the $\operatorname{Ar}$ laser $(\lambda=514.5 \mathrm{~nm})$. It should be noted that, despite the high concentration of the Er atoms in $\mathrm{Si}\left(N>10^{21} \mathrm{~cm}^{-3}\right)$ and erbium precipitation in the form of optically inactive silicides, the PL peak at $0.806 \mathrm{eV}$, caused by optical transitions between the ${ }^{4} I_{13 / 2} \longrightarrow{ }^{4} I_{15 / 2}$ levels of the $\mathrm{Er}^{3+}$ ion, exists in the spectra of both samples. In our opinion, the light-emitting region responsible for erbium PL at $0.806 \mathrm{eV}$ is mostly localized in the extended tail regions of the profile of the impurity distribution, in which an Er solid solution in $\mathrm{Si}$ is formed. The Er concentration in these regions is $10^{18}-10^{20} \mathrm{~cm}^{-3}$ which is significantly lower than near the surface. We also note that the Er peak at $0.806 \mathrm{eV}$ is overlapped with a broad peak in the energy range of $0.75-0.9 \mathrm{eV}$ in the PL spectrum of the second sample. The latter peak is probably associated with the formation of dislocation structures in the layer due to high-dose implantation and thermal annealing. Thus, despite the high concentration of erbium and its precipitation in the form of silicides, the obtained layers exhibit photoluminescence properties in the near-IR region, which allows the development of efficient lightemitting diodes on their basis.

\section{CONCLUSIONS}

The formation of Er solid solutions in $\mathrm{Si}$ and synthesis of erbium silicides using highly nonequilibrium methods, i.e., continuous ion implantation and pulsed treatment, were studied. The following results were obtained.

Pulsed treatment of Si layers implanted with a rather low dose of $\mathrm{Er}^{+}$ion $\left(\Phi=10^{16} \mathrm{~cm}^{-2}\right)$ results in epitaxial crystallization of the amorphous implanted layer with the formation of cellular structures with Si cell sizes to $0.2 \mu \mathrm{m}$ and preferential displacement of Er atoms to the surface layer to $30 \mathrm{~nm}$ thick (segregation).

Pulsed treatment of Si layers implanted with a high dose of $\mathrm{Er}^{+}$ion $\left(\Phi=10^{17} \mathrm{~cm}^{-2}\right)$ results in unoriented crystallization of the amorphous layer with the formation of polycrystalline erbium disilicide $\mathrm{ErSi}_{2}$ with grain sizes up to $40 \mathrm{~nm}$ and diffusion redistribution of Er impurity to the Si crystal depth.

High-dose ion implantation and nanosecond pulsed treatments allow the formation of layers emitting in the near-IR region with erbium impurity concentration significantly exceeding the precipitation threshold.

\section{ACKNOWLEDGMENTS}

This study was supported in part by the Russian Foundation for Basic Research, project no. 08-02-01280, program "New Materials and Structures" of the Physical Science Division of the Russian Academy of Sciences, and the Russian Science Support Foundation.

\section{REFERENCES}

1. A. J. Kenyon, Semicond. Sci. Technol. 20, R65 (2005).

2. A. Polman, J. Appl. Phys. 82, 1 (1997).

3. X. Q. Cheng and B. X. Liu, J. Alloys Compd. 336, 253 (2002).

4. N. A. Sobolev, A. M. Emel'yanov, E. I. Shek, et al., J. Phys.: Condens. Matter 14, 13241 (2002).

5. A. V. Dvurechenskii, G. A. Kachurin, E. V. Nidaev, and L. S. Smirnov, Pulsed Annealing of Semiconductor Materials (Nauka, Moscow, 1982) [in Russian].

6. J. Michel, J. L. Benton, R. F. Ferrante, et al., J. Appl. Phys. 70, 2672 (1991).

7. R. Bayazitov, R. Batalov, R. Nurutdinov, et al., Nucl. Instrum. Methods Phys. Res. B 24, 224 (2005). 